\title{
Functional Outcome of Arthroscopically Assisted Anterior Cruciate Ligament Reconstruction
}

\author{
Dr.S.Sasibhushana Rao ${ }^{1}$, Dr.V.Chiranjeevi ${ }^{2}$, Dr.S.David Raju ${ }^{3}$. \\ 1. Associate Professor Of Orthopaedics Department,Department Of Orthopaedics, MIMS Medical College And \\ Hospital, Nellimarla, Vizianagaram,Andhra Pradesh, India. \\ 2. Senior Resident,Department Of Orthopaedics, MIMS Medical College And Hospital, Nellimarla, \\ vizianagaram,Andhra Pradesh, India. \\ 3. Professor and HOD Of Orthopaedics Department,Department Of Orthopaedics, MIMS Medical College And \\ Hospital, Nellimarla, Vizianagaram, Andhra Pradesh, India.
}

\begin{abstract}
Anterior cruciate ligament (ACL) tear is the most common ligamentous tear of knee joint. The goal of reconstruction of ACL is to restore the stability of knee joint. This study is to evaluate the functional outcome of Arthroscopically assisted ACL reconstruction using Bone patellar tendon bone graft and quadrupled hamstring graft. Our study of 30 cases of arthroscopic ACL reconstruction(21 Bone patellar tendon bone graft, 9 Quadrupled Hamstrig Graft). We have evaluated th knee function pre and post operatively using international knee documentation committee(IKDC) and Lysholm score. Our study showed that Arthroscopically assisted $A C L$ reconstruction could effectively improve stability and function of knee joint. Our results were almost similar to the results obtained in the standard published literature.
\end{abstract}

Key Words: Anterior cruciate ligament, Bone patellar tendon bone graft, I nternational knee documentation committee, Quadrupled hamstring graft, Lysholm score.

\section{Introduction}

Anterior cruciate ligament (ACL) tear is the most common serious ligamentous injury to the knee joint $1,{ }^{2}$. The ACL is the primary stabilizer against anterior translation of the tibia on the femur ${ }^{3}$ and is important in counteracting rotation and valgus stress. Anterior cruciate ligament deficiency leads to knee instability. This results in recurrent injuries and increased risk of intra-articular damage, especially the meniscus 4,5 . The goals of the ACL reconstruction are to restore stability to the knee; allow the patient to return to normal activities, including sports; and to delay the onset of osteoarthritis with associated recurrent injuries to the articular cartilage and loss of meniscal functions ${ }^{6-8}$. During the past decade arthroscopically assisted techniques have been an accepted method of reconstructing the $\mathrm{ACL}^{8-10}$. Despite an abundance of literature on ACL reconstruction and its outcome, there are little data directly comparing hamstring tendon autograft and patellar tendon autograft to aid the patient and surgeon in selecting the appropriate graft ${ }^{11}$. There is little or no difference between bone-patellar tendon-bone and combined semitendinosus and gracilis hamstring tendon grafts in terms of the functional outcome after ACL reconstruction, despite greater laxity measurements in the hamstring tendon group patients. This suggests that operating surgeon must decide how to select the appropriate graft for an individual patient ${ }^{12}$. Graft choice, Surgeon experience, correct graft position, choice the graft fixation, and postoperative rehabilitation confound the results of comparison of ACL reconstruction 13 . Stiffness and strength tend to be slightly better with bone-patellar tendon-bone, but overall results are comparable 14 .

The advantages of arthroscopically assisted anterior cruciate ligament reconstruction include elimination of capsular incisions, decrease in trauma to the fat pad, avoidance of desiccation of the articular cartilage, better visualization of the femoral attachment, and a lower incidence of post-operative patellofemoral pain than with open reconstruction ${ }^{15}$.The primary disadvantage of arthroscopically assisted technique is that the technique has a long learning curve and is a technically demanding prodecure ${ }^{16}$.

The bone-patellar tendon-bone and the hamstring tendon are the two most commonly used autografts for reconstruction 17,21. The bone-patellar tendon-bone graft has been widely accepted as gold standard for ACL rconstruction with high success rate.however donor site morbidities and extensor mechanism problems assosciated with bone-patellar tendon-bone graft have led to increasing popularity of hamstring tendon graft which had advantages of low donor site morbidities, avoidance of extensor mechanism problems and better cosmesis. In our study we have analyzed the results of Arthroscopic ACL reconstruction using autologous ipsilateral bone patellar tendon bone graft and quadrupled hamstring graft. 


\section{Materials And Methods}

Between June 2010 to September 201330 consecutive patients who underwent arthroscopic assisted ACL reconstructions in the Department of Orthopaedics and Traumatology, Maharajah's institute of medical sciences, Nellimarla, Vizianagaram is the material in our study. After the patient is clinically and radiologically (Magnetic Resonance Imaging) diagnosed to have tear, and after meeting inclusion criteria, the patients were taken up for Arthroscopic ACL reconstruction. All the patients were followed up at regular interval i.e. 3 months, 6 months, 12 months and 18 months and 24 months (prospective study). The outcome was evaluated in all cases at the latest follow-up (at least 6 months). In patients with BPTB graft it was fixed with titanium interference screws on femoral and tibial side. In patients with hamstring graft it was fixed with interference screws on tibial side and transfix screw on femoral side .

Fig 1

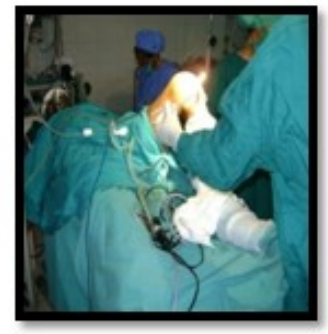

Making portals of Arthroscopy

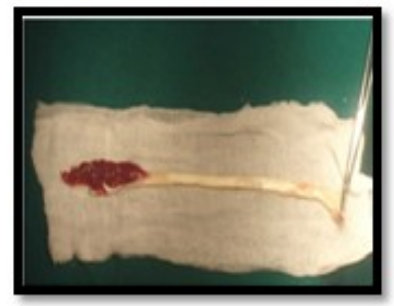

Hamstring Graft

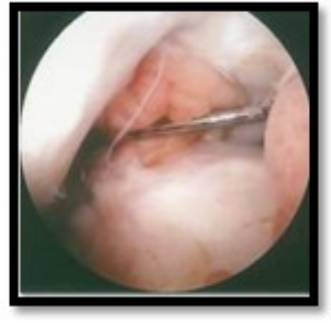

Arthroscopic view of ACL tear

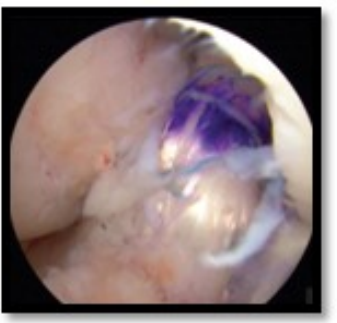

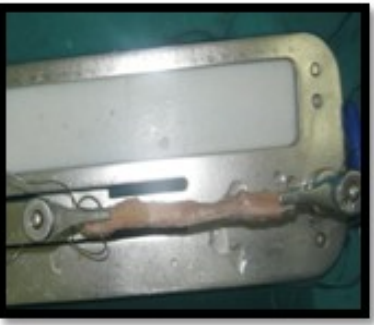

Harvested BPTB Graft

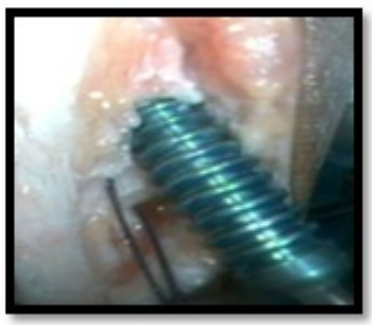

Arthroscopic View Of ACL Graft \& Interference Screw On Tibial Side

\section{Results}

In our study of Arthroscopic Cruciate Ligament reconstruction, a total of 30 cases were operated and followed up. Minimum follow up period was six months and maximum follow up period was twenty four months period.

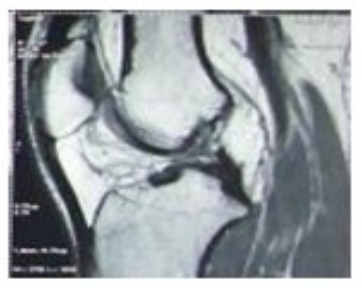

Mri Scan

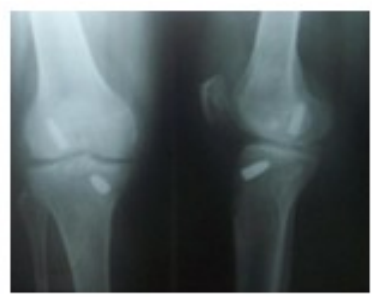

Post Op radiograph

Fig 2(BPTB graft)

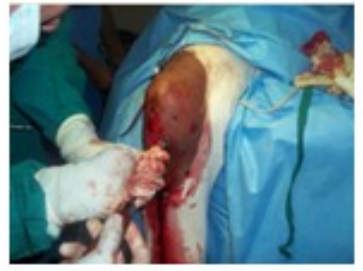

Intra Op Photo

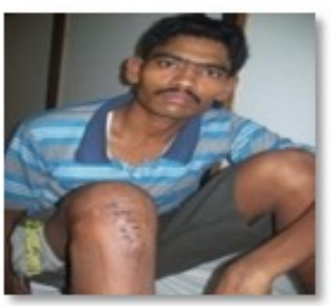

Post operative scar

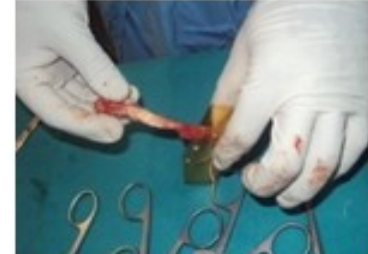

Per Op Graft Preparation

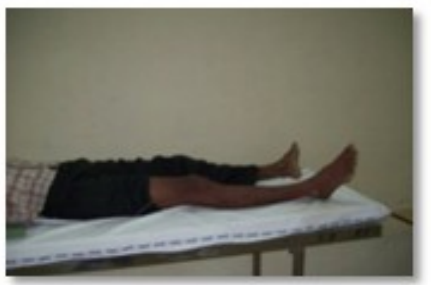

post op extension 


\section{Fig 3(Hamstring graft)}

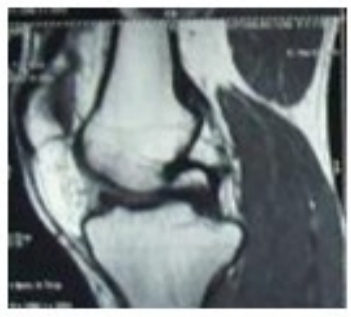

Mri Scan

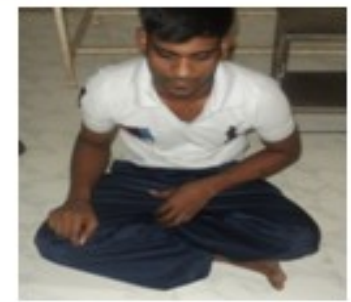

Post Op Cross Leg Sitting

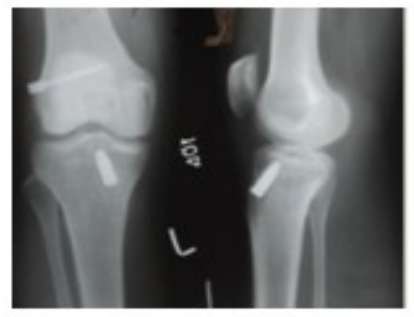

Post Op Radiograph

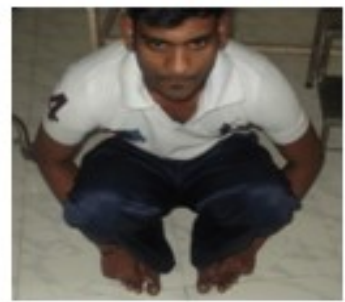

Post Op Squatting

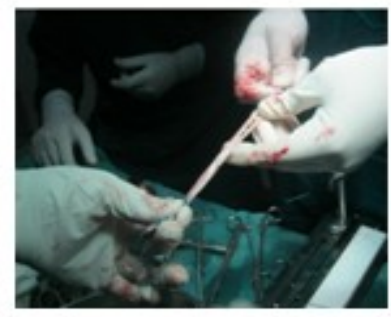

Hamstring Graft

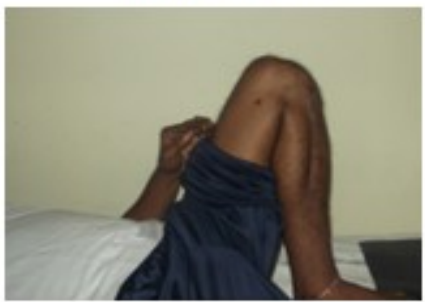

Post Op Flexion

In our study Lysholm score was done at pre op, 3 months, 6 months, 1 year, 18 months and 2 years. Average Lysholm score at pre op 52.9, 3 months 82.2, at 6 months 89, at 1 year 91.4, 18 months 93.5 and at 2 years 94.8. There was clinically significant improvement in Lysholm score pre operative period (52.9) to 6 months post operative period (89) with p value $<0.01$.

In our study IKDC score was done at pre op, 3 months, 6 months, 1 year, 18 months and 2 years. Average IKDC score at pre op 48.8, 3 months 85.8, at 6 months 89.8, at 1 year 92, 18 months 93 and at 2 years 93.5. There was clinically significant improvement in Lysholm score pre operative period (48.8) to 6 months post operative period (89.8) with p value $<0.01$.

\section{Discussion}

Average age at surgery in the present study group was 26 years and that of D Choudhary et al. 2005 was 27 years and that of Jomha et al. 1999 was 26 years and Raileyet al. 2004 was 33 years and Mahir et al. 2005 was 24 yrs. Average duration of follow-up of the present study was 13 months with a minimum follow-up period 6 months and maximum follow-up period was 24 months. Average duration of follow-up D Choudhary et al. 2005 was 12 months and that of Jomha et al 1999 was 84 months, Railey et al. 2004 was 24 months, Mahir et al. 2005 was 18 months. The measured Lysholm score of D Choudhary et al. 2005 at the end of the study was 92, Jomha et al. 1999 at the end of the study was 94, Railey et al. 2004 at the end of the study was 91, Mahir et al.2005 was 93.5 and our study average Lyshom score at end of the study is 92.5 .

\section{Conclusion}

Majority of study subjects were males i.e., 30 out of 30. Patients with isolated ACL injury had better outcome compared to patients who underwent associated meniscectomy. $(\mathrm{P}<0.05)$. There is significant pre operative to post operative improvement in knee functional scores both Lysholm and IKDC ( $\mathrm{P}<0.01)$. Post operatively at 3 months anterior drawer's was $1+$ in $17 \%$ patients which improved with rehabilitation in all patients. Post operatively at 3 months $90 \%$ patients had normal range of motion. Post operatively at 3 months $80 \%$ patients had 5/5 quadriceps power (MRC grading) $94 \%$ of them had 5/5 power at latest follow up. In our study we had various complications like Anterior Knee Pain, Superficial infection and Deep infection which were treated. Autologous ipsilateral bone patellar tendon bone graft and quadrupled hamstring graft have produced good to excellent post operative functional scores which clinically significant.

\section{REFERENCES}

[1]. Miyasaka KC, Daniel DM, Stone ML. The incidence of knee ligament injuries in the general population. Am J Knee Surg 1991; 4:3-8.

[2]. Noyes FR, Bassett RW, Grood ES, Butler DL. Arthroscopy in acute traumatic hemarthrosis of the knee. Incidence of anterior cruciate tears and other injuries. J Bone Joint Surg(Am) 1980; 62: 687-95, 757.

[3]. Levy IM, TorzilliPA,WarrenRF. The effect of meniscectomy on anterior-posterior motion of the knee. J Bone Joint Surg (Am) 1982; 64: 883-8. 
[4]. Jomha NM, Pinczewski LA, Clingeleffer A, Otto A. Arthroscopic reconstruction of anterior cruciate ligament with patellartendon autograft and interferrence screw fixation. The results at seven years. J Bone Joint $\operatorname{Surg}(\mathrm{Br})$ 1999; 81: 775-9.

[5]. Barrack RL, Bruckner JD, Knist J, Inman WS, Alexander AH. The outcome of non-operatively treated complete tears of the anterior cruciate ligament in active young adults. Clin Orthop1990; 259: 192-9.

[6]. Dye SF, Wojtys EM, Fu FH, Fithian DC, Gillquist J. Factors contributing to function of the knee joint after injury and reconstruction of the anterior cruciateligament. In Zuckerman JD.Ed.Instructional Course lecture. Rosemont, American Academy of Orthopedic Surgery.1999; 48: 185-98.

[7]. Jorgensen U, Sonne-Holm U, Lauridsen F, Rosenklint A. Long term follow-up of meniscectomy in athletes. J Bone Joint Surg(Br) 1987; 69: 80-3.

[8]. Rangger C, Klestil T, Gloetzer W, Kemmler G, Benedetto P.Osteoarthritis after arthroscopic partial meniscectomy Am J Sports Med 1995; $23: 240-4$.

[9]. Arciero RA, Scoville CR, Snyder RJ, Uhorchak JM, Taylor DC, Huggard DJ. SingleVersus two incision Arthroscopic Anterior Cruciate Ligament ReconstructionJ Arthroscopy 1996; 12: 462-9.

[10]. Buss DD, Warren RF, Wickiewicz TJ, Galinat BJ, Panaviello R. Arthroscopically assisted reconstruction of the anterior cruciate ligament with use of autogenous patellar ligament grafts. Results after twenty-four to forty-two months, J Bone Joint Surg (Am) 1993; 75: 1346-5

[11]. MatjazSajovic, MD, VilibaldVengust, MD, RadkoKomadina, MD, RokTavcar, MD, and KatjaSkaza, PT, A Prospective, Randomized Comparison of Semitendinosus and Gracilis Tendon Versus Patellar Tendon Auto grafts for Anterior Cruciate Ligament Reconstruction Five-Year Follow-Up Am. J. Sports Med. 2006; 34; 1933.

[12]. Julian A. Feller, FRACS, and Kate E. Webster, PhD, A Randomized Comparison of Patellar Tendon and Hamstring Tendon Anterior Cruciate Ligament Reconstruction, Am. J. Sports Med. 2003; 31; 564

[13]. Leo A. Pinczewski, FRACS, Jeffrey Lyman, MD, Lucy J. Salmon, PhD, Vivianne J. Russell, BSc (Biomed), Justin Roe, FRACS, and James Linklater,FRANZCR, A 10-Year Comparison of Anterior Cruciate Ligament Reconstructions With Hamstring Tendon and Patellar Tendon Auto graft A Controlled, Prospective Trial Am. J. Sports Med. 2007; $35 ; 564$.

[14]. Barry B. Phillips, Campbell's operative orthopedics, Tenth edition, chapter 48

[15]. . Fu FH, Schulte KR. Anterior cruciate ligament surgery 1996.State of the art. ClinOrthop1996; 325: 19-24.

[16]. Meade TD, Dickson TB. Technical pitfalls of a single incision arthroscopically assisted ACL reconstruction. Am J Arthroscopy $1992 ; 2: 15-9$. 